\title{
The density of humic acids and humic like substances (HULIS) from fresh and aged wood burning and pollution aerosol particles
}

\author{
E. Dinar ${ }^{1}$, T. F. Mentel $^{2}$, and Y. Rudich ${ }^{1}$ \\ ${ }^{1}$ Department of Environmental Sciences, Weizmann Institute of Science, Rehovot 76100, Israel \\ ${ }^{2}$ Institute for Tropospheric Chemistry, Research Center Jülich, Jülich, Germany \\ Received: 25 July 2006 - Published in Atmos. Chem. Phys. Discuss.: 11 August 2006 \\ Revised: 18 October 2006 - Accepted: 9 November 2006 - Published: 16 November 2006
}

\begin{abstract}
Atmospheric aerosols play significant roles in climatic related phenomena. Size, density and shape of particles affect their fluid-dynamic parameters which in turn dictate their transport and lifecycle. Moreover, density and shape are also related to particles' optical properties, influencing their regional and global radiative effects. In the present study we have measured and compared the effective densities of humic like substances (HULIS) extracted from smoke and pollution aerosol particles to those of molecular weight-fractionated aquatic and terrestrial Humic Substances (HS). The effective density was measured by comparing the electro mobility and vacuum aerodynamic diameter of aerosol particles composed of these compounds. Characterization of chemical parameters such as molecular weight, aromaticity and elemental composition allow us to test how they affect the effective density of these important environmental macromolecules. It is suggested that atmospheric aging processes increase the effective density of HULIS due to oxidation, while packing due to the aromatic moieties plays important role in determining the density of the aquatic HS substances.
\end{abstract}

\section{Introduction}

Tropospheric aerosols alter climate (Hansen et al., 2005; Kaufman et al., 2005, 2002; Koren et al., 2005; Lohmann et al., 2006; Poschl, 2005; Ramanathan et al., 2001), visibility (Cheng and Tsai, 2000; Malm et al., 2003) and human health (Huang et al., 2003; Kappos et al., 2004; McDonnell et al., 2000). The key for understanding how atmospheric aerosols affect these issues depends on our knowledge of their physical and chemical properties. Aerosol properties such as size, shape, density, hygroscopic growth under subsaturation conditions, activation to cloud condensation nuclei ( $\mathrm{CCN})$ under

Correspondence to: Y. Rudich

(yinon.rudich@weizmann.ac.il) supersaturation conditions and optical properties are all ruled by the coupling between the "chemical composition" of the particle and the "physical processes" the particle undergoes.

It is now recognized that organic compounds comprise a substantial mass fraction of tropospheric aerosols, up to $90 \%$ in some cases (Jacobson et al., 2000; Kanakidou et al., 2005; Novakov and Penner, 1993). The organic fraction is composed of hundreds to thousands of individual species (Saxena and Hildemann, 1996), many of them contributing only a small fraction to the overall particle mass. The organic fraction is often classified on the basis of water solubility, with the water soluble organic carbon (WSOC) fraction making up the major portion of atmospheric organic matter (Facchini et al., 1999; Saxena and Hildemann, 1996; Zappoli et al., 1999). Between 20-70 wt\% of the water soluble organic carbon (WSOC) fraction are high molecular weight (HMW) polycarboxylic acids (Graber and Rudich, 2006, and references therein); a heterogeneous mixture of structures containing aromatic, phenolic and acidic functional groups (Decesari et al., 2001; Diallo et al., 2003; Gysel et al., 2004; Kiss et al., 2002; Krivacsy et al., 2001; Mayol-Bracero et al., 2002; Varga et al., 2001). These heterogeneous structures bear a certain resemblance to humic substances (HS) from terrestrial and aquatic sources. Therefore, these aerosolassociated compounds are referred to in the atmospheric chemistry literature as HUmic-LIke Substances (HULIS).

The chemical and physical properties of aquatic and terrestrial HS have been extensively studied due to their important role in affecting soil properties and their presence in water bodies. However, to the best of our knowledge, measurements of their bulk densities are scarce and were mostly performed in solution, hence they are affected by $\mathrm{pH}$ and ionic content. As far as we know the bulk density for both terrestrial and aquatic HS has never been measured directly. Since these species are inhomogeneous mixtures, and often are not separated from other soil components and since they are assumed to be dissolved in the water, the literature usually

Published by Copernicus GmbH on behalf of the European Geosciences Union. 
refers to their partial specific volume (Benedetti et al., 1996; Jones et al., 1995; Reid et al., 1990). In the last decade, the interest of atmospheric sciences in these substances has expanded due to the resemblance of atmospheric HULIS to HS in chemical nature and physical properties (Gelencser et al., 2000; Hoffer et al., 2004; Kiss et al., 2002).

The chemical properties of both terrestrial and aquatic HS and atmospheric HULIS have been investigated during the last decade. A few experimental and modeling studies have tried to connect chemical characterization to physical atmospheric properties such as: 1) CCN activity (Dinar et al., 2006b; Svenningsson et al., 2005), 2) hygroscopicity (Badger et al., 2006; Brooks et al., 2004; Chan and Chan, 2003; Dinar et al., 2006a; Gysel et al., 2004; Svenningsson et al., 2005) and 3) optical properties (Hoffer et al., 2006; Schkolnik and Rudich, 2006). Even though terrestrial and aquatic HS have long been studied and the importance of HULIS in atmospheric aerosol is recognized, as far as we know, no report of their density has been published.

Generally, the density of a particle is an important physical property, because it relates the aerodynamic diameter with the Stokes diameter, which equals the geometric diameter in case of a compact sphere. It relates the particle's volume (which is typically calculated from sizing measurements) with the mass or with the number of moles of the substrate. Thus density of a particle affects its fluid-dynamic parameters which dictate its transport and lifecycle (such as: terminal velocities under acting forces in viscous media, coagulation, distance of transport from source, dry deposition). Density of particles is related to: 1) the solute effect in the (mass based) Köhler equation for droplet activation, 2) the water content of particles, 3) particle optical properties (Tang and Munkelwitz, 1994), and finally 4) the density can be used as a tool to monitor chemical transformation in the particle (Katrib et al., 2005). Nevertheless, until recently very few studies report on aerosol densities, probably due to technical limitation in direct experimental measurements. Up to date, the density of a particle was deduced based on knowledge of its chemical composition (Hasan and Dzubay, 1983) or derived separately by measuring aerosol mass and aerosol volume (Hanel and Thudium, 1977; Pitz et al., 2003). In recent years, new methods have been applied for measuring particles' effective density mostly by combining different aerosol measurements techniques (McMurry et al., 2002; Murphy et al., 2004). The most recently used approach for measuring particles density is based on combined measurements of the electric mobility diameter $\left(d_{b}\right)$ and the aerodynamic diameter $\left(d_{a}\right)$, from which the particle effective density $\rho_{\text {eff }}$ can be derived (DeCarlo et al., 2004). The effective density can be related to particles' bulk density under some assumptions about the particle average dynamic shape factor $\bar{\chi}$ (DeCarlo et al., 2004; Jayne et al., 2000; McMurry et al., 2002; Slowik, 2004; Zelenyuk et al., 2005; Zelenyuk and Imre, 2005), which is a measure of how spherical the particle is.
In the present study we report on the measured effective densities for HULIS isolated from atmospheric aerosols, for Fulvic Acid (FA) and for Humic Acid (HA) samples from aquatic and terrestrial sources. Since these samples have been chemically characterized and intensively studied for their sub-saturation hygroscopic growth (HG) (Dinar et al., 2006a) and CCN activity under supersaturation conditions (Dinar et al., 2006b), we aim here on correlating between measured effective density of the particles to their chemical and physical properties.

\section{Experiment}

\subsection{Samples description}

\subsubsection{HULIS samples}

Atmospheric HULIS compounds were isolated from collected aerosol particles. Aerosols were sampled during an aerosol sampling campaign which started on the night of an extensive, nation-wide wood burning event and continued later into the summer with sampling of pollution particles. The collected samples were: 1) Fresh smoke particles (termed hereafter "LBO-night") sampled throughout the night (26-27 May 2005) with average PM10 mass concentrations near the sampling location of $\left.300-400 \mu \mathrm{g} \mathrm{m}^{-3}, 2\right)$ slightly aged wood burning smoke particles (termed hereafter "LBO-day") which were sampled during daytime, following the nighttime fires (27 May 2005), with PM10 mass concentrations of $60-180\left(\mu \mathrm{g} \mathrm{m}^{-3}\right)$ and, 3) Pollution particles (called hereafter " 3 WSFA") which were collected during daytime only over a three week period (26 July to 16 August 2005), with average PM10 mass concentration of about $25 \mu \mathrm{g} \mathrm{m}^{-3}$. The "LBO-night" sample is dominated by freshly emitted smoke particles, without photochemical processing. The "LBO-day" sample is dominated by smoke particles (as concluded from the high aerosol mass concentrations and the dark color of the collected particles), but could have undergone moderate processing via photochemical reactions and mixing with photochemical pollution. The "3WSFA" sample contains the prevailing local photochemical pollution aerosol particles, and is assumed to represent aged particles. Operationally-defined FA were extracted from the filters and separated from the other particles' components by an isolation procedure developed on the basis of the scheme used by the International Humic Substances Society (IHSS) for aquatic HS (http://www.ihss.gatech.edu), and adapted for air-borne particulate matter collected on quartz fiber filters. Briefly, filters are subjected to consecutive water and water-base extractions; FA HULIS (by definition soluble at any $\mathrm{pH}$ ) were separated from other water soluble and base-soluble aerosol organic and inorganic species by preferential absorption onto an XAD-8 resin, followed by elution in a basic solution. The eluant was cation-exchanged on 
an H+-saturated cation-exchange resin (AG MP-50, Bio-Rad Laboratories) to produce protonated acids, and then freezedried. At stages where oxidation can occur, an inert atmosphere $\left(\mathrm{N}_{2}\right)$ was applied. The freeze-dried samples are stored at room temperature in darkness under vacuum. $18 \mathrm{MOhm}$ Mill-Q water was used for all solutions throughout the study. For detailed sampling and extraction procedures see Dinar et al. (2006b).

\subsubsection{Humic substances samples}

Two HS reference samples were also used as model for atmospheric HULIS, Suwannee River Fulvic Acid (SRFA, IHSS code 1R101F) and Pahokee Peat Humic Acid (PPHA, PP soil, IHSS code 2BS103P, for extraction procedure see Dinar et al. (2006b) and Swift (1996) and the protocol of the IHSS, http://www.ihss.gatech.edu/). The SRFA was chosen since several previous laboratory studies referred to it as a representative of atmospheric HULIS (Abdul-Razzak and Ghan, 2004; Brooks et al., 2004; Chan and Chan, 2003; Fuzzi et al., 2001; Haiber et al., 2001; Kiss et al., 2005; Mircea et al., 2002; Nenes et al., 2002; Rissman et al., 2004; Samburova et al., 2005; Svenningsson et al., 2005). Pahokee Peat HA was chosen because it extends our knowldege into humic acid, which may also be representative of some of the higher molecular weight species in atmospheric aerosol particles. Both HS samples were de-ashed and cleaned from low molecular weight organic acids and inorganic species (Dinar et al., 2006b). This was verified by ion chromatographic analysis.

The SRFA and PPHA samples are known to contain compounds with a wide distribution of molecular weights. In order to study how effective density depends on molecular parameters, both HS samples were coarsely divided according to the effective size of the molecules in solution using ultra-filtration. Five size fractions of water-soluble material denoted F1, F2, F3, F4, and F5, from low to high MW respectively, were obtained for each sample.

\subsection{Samples characterization}

The SRFA samples were characterized by various means (estimated mean molecular weight was characterized by UV absorption, elemental analysis, and surface tension measurements (unpublished results)). The HULIS samples were also characterized in a similar manner. It is explicitly assumed that the UV correlations for SRFA hold for fulvic acid HULIS studied here. Detailed description and discussion of the characterization used and its results can be found in Dinaret al. (2006b).

\subsection{Aerosol generation}

All investigated aerosols were prepared by nebulizing aqueous solutions: $20-50 \mathrm{mg} / \mathrm{L}$ for ammonium sulfate (AS), ammonium bisulfate (ABS), glucose, and HS samples (bulk and fractions), and 10-20 mg/L for atmospheric HULIS samples. Monodisperse polystyrene latex spheres (PSL, Duke Scientific, density $1.05 \mathrm{~g} / \mathrm{cm}^{-3}$ ) solutions were prepared by diluting the commercial stock. The solutions were atomized using a TSI constant output atomizer (TSI-3076) operating at 30 PSI $(\sim 3$ standard liters per minute (SLM)) with dry particle-free synthetic air (mixed liquid nitrogen and oxygen, Linde 6.0) generating a polydisperse distribution of droplets of mean diameter $\sim 0.3 \mu \mathrm{m}$.

\subsection{System setup and the measurement principles}

Aerosols' effective density was measured based on the relationship between electric mobility and vacuum aerodynamic diameters ( $d_{b}$ and $d_{v a}$ respectively). The electromobility diameter $d_{b}$ for particles of arbitrary shape is given by (compare DeCarlo et al., 2004):

$d_{b}=d_{v e} \cdot \frac{C_{c}\left(d_{b}\right)}{C_{c}\left(d_{v e}\right)} \cdot \chi_{b}$

where $d_{v e}$ is the particle volume equivalent diameter, $\chi_{b}$ is the dynamic shape factor for the regime in the selecting DMA, $C_{c}(d)$ is the Cunningham slip correction factor. The aerodynamic diameter $d_{a}$ for particles of arbitrary shape and density is given by (compare Baron and Willeke, 2001):

$d_{a}=d_{v e} \sqrt{\frac{1}{\chi_{b}} \frac{\rho_{p}}{\rho_{0}} \frac{C_{c}\left(d_{v e}\right)}{C_{c}\left(d_{b}\right)}}$

where $\rho_{p}$ and $\rho_{0}$ are particle density and unit density. When the aerodynamic diameter is measured under vacuum $\left(d_{v a}\right.$, vacuum dynamic diameter, $\chi_{v a}$ dynamic shape factor in the vacuum dynamic regime), i.e. in the so called molecular regime, Eq. (1b) can be simplified to: (DeCarlo et al., 2004; Slowik, 2004; Zelenyuk et al., 2005)

$d_{v a}=\frac{\rho_{p}}{\rho_{0}} \cdot \frac{d_{v e}}{\chi_{v a}}$

For spherical particles $(\chi=1)$ of density $\rho_{p} d_{b}=d_{v e}=d_{p}$ with $d_{p}$ being the geometrical diameter. Combining Eqs. (1a) and (2a) yields the expression for the particle density of spherical particles derived from simultaneous measurements of the electromobility and the vacuum aerodynamic diameters:

$\rho_{p}=\rho_{0} \frac{d_{v a}}{d_{b}}$

For aspheric particles there is need to account for shape effects on $d_{b}$ and $d_{v a}$. For $\chi>1, d_{b}$ increases (since the drag forces of the drift in the electrical field increase with asphericity), whereas $d_{v a}$ decreases (since with increasing irregularity the effective density decreases due to the increasing ratio of $d_{v e}$ to $d_{\text {Stokes }}$ of the sphere made of the same mass and the same density $\rho_{p}$ ). This behavior makes the ratio $d_{v a} / d_{b}$ very sensitive to changes in particles' $\chi$. If $\chi$ is unknown, it is still possible to define an effective density, 


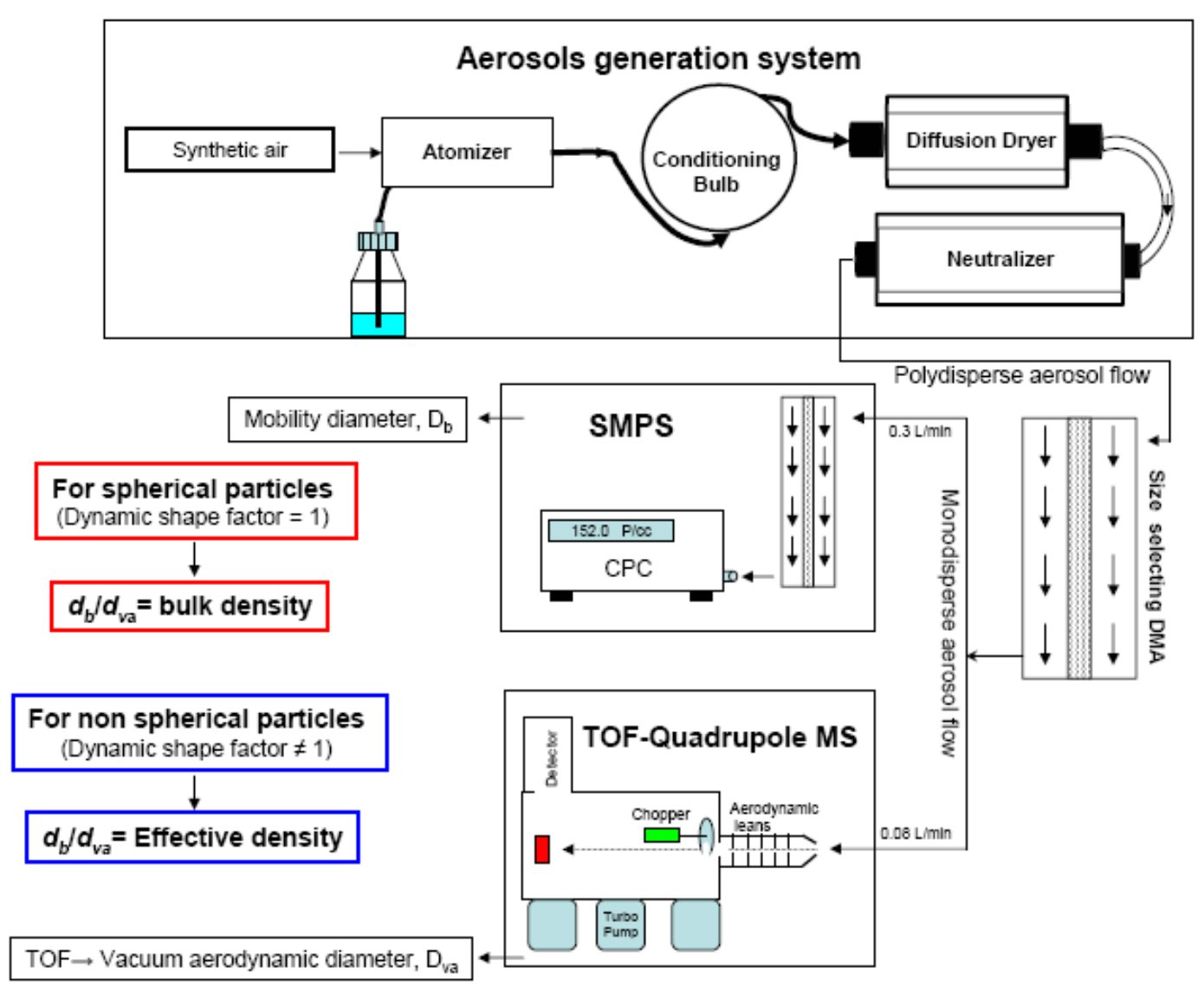

Fig. 1. A schematic illustration presenting the system setup used for density measurements. The top box presents the aerosol generation part from solution to a dry and charged polydisperse aerosol flow. The flow is then introduced to the size selection DMA resulting with a narrow size-selected aerosol flow which is split to the AMS (measures the vacuum aerodynamic diameter) and the SMPS (measures the electromobility diameter).

$\rho_{\text {eff }}$, (Jimenez et al., 2003) where $\rho_{0}$ is the standard density $\left(1 \mathrm{~g} \mathrm{~cm}^{-3}\right)$ :

$\rho_{\mathrm{eff}}=\rho_{0} \frac{d_{v a}}{d_{b}}$

with

$\rho_{\mathrm{eff}}=\rho_{p} \cdot S^{\prime}$

and

$S^{\prime}=\frac{C_{c}\left(d_{v e}\right)}{C_{c}\left(d_{b}\right)} \cdot \frac{1}{\chi_{b} \cdot \chi_{v a}}$

Detailed discussion of the relations between particles density, morphology and their effect upon electromobility and aerodynamic diameters is discussed by DeCarlo et al. (2004), Zelenyuk et al. (2005), Slowik et al. (2004), Katrib et al. (2005), McMurry et al. (2002) and Park et al. (2003, 2004).

The experimental apparatus is shown in Fig. 1. A humid polydisperse droplet flow is produced by nebulizing aqueous solutions. In previous experiments we identified the need to let the particles equilibrate for a few minutes in a buffer volume after nebulizing and before drying (Dinar et al., 2006a, b). The conditioning step affected the particles diameter of activation under supersaturated conditions, and avoided compaction of the particles upon drying in dehydration experiments at sub-saturated conditions (i.e. reaching growth factors less than one) (Dinar et al., 2006a). Therefore we employed conditioning also in the present experiments; the fresh flow of droplets reached equilibrium with the surrounding environment in a $2-1$ conditioning bulb before entering a silica gel diffusion drier. The resulting dry polydisperse aerosol flow (relative humidity $(\mathrm{RH})<3 \%$ ) was neutralized using a ${ }^{85} \mathrm{Kr}$ neutralizer, and then size selected by a differential mobility analyzer (DMA, TSI Inc., Model 3071). This yields a narrow monodisperse size distribution with a known electromobility diameter $d_{b}$. Particles ranging between $d_{b}$ of 85-150 nm (organics) and 80-230 nm (ammonium salts) were selected by the DMA, which was operated with 3 SLM dry sheath flow of $\mathrm{RH}<3 \%$. Upon exiting the DMA, the dry monodisperse aerosol flow of 0.38 SLM was split, 0.3 SLM was directed to a second DMA operating as a scanning mobility particle sizer (SMPS, TSI Inc. 3071) 
Table 1. Effective densities measured for the validation compounds. The reciprocal of the Jayne shape factor (ratio between the effective density to the bulk/crystalline density), $1 / \mathrm{S}$ is also presented. For small $\chi$, and for particles in the range $100-200 \mathrm{~nm}$ in diameter the square root of $1 / \mathrm{S}$ is a good estimate of the dynamic shape factor, $\chi$.

\begin{tabular}{lllll}
\hline & Effective density $\left(\mathrm{g} \mathrm{cm}^{-3}\right)$ & $1 / \mathrm{S}$ & $\begin{array}{l}\text { Bulk density } \\
\left(\mathrm{g} \mathrm{cm}^{-3}\right)\end{array}$ & Literature \\
\hline Ammonium sulfate (AS) & $1.75 \pm 0.03$ & $1.01 \pm 0.02$ & 1.77 & $\begin{array}{l}\text { Depends on particle size } \\
\text { (Zelenyuk et al., 2005) }\end{array}$ \\
& & & 1.74 (Tang et al., 1994) \\
Ammonium bisulfate (ABS) & $1.74 \pm 0.02$ & $1.03 \pm 0.01$ & 1.79 & $\begin{array}{l}1.77 \text { (Zelenyuk et al., 2005) } \\
\text { Glucose }\end{array}$ \\
& $1.53 \pm 0.02$ & $1.00 \pm 0.02$ & 1.54 & 1.54 (CRC handbook) \\
& & & & \\
\hline
\end{tabular}

in conjugation with a condensation particle counter $(\mathrm{CPC}$, TSI Inc., Model 3022A), and 0.08 SLM were directed to an aerosol mass spectrometer AMS (Aerodyne Research Inc.) (Jayne et al., 2000). The SMPS determined $d_{b}$ of the selected particles, while $d_{v a}$ of the particles was simultaneously determined in particle time of flight (PToF) mode by the AMS.

\section{Results and discussion}

\subsection{DMA and AMS calibration and system setup validation}

The first DMA and the SMPS DMA were calibrated for measuring mobility diameters ranging from 50 to $199 \mathrm{~nm}$ using a set of certified polystyrene latex (PSL) spheres (Duke Scientific; 50, 81, 102, 152, $199 \mathrm{~nm}$ ). By careful control of the flows and relative humidity, the aerosol size mode was highly reproducible and a daily calibration curve was applied for the entire mobility diameter range under investigation. It is noted however that the DMA transfer function has a systematic uncertainty of $\pm 3 \%$ from the mean diameter.

The AMS alternated between acquiring mass spectra (MS) and PToF mode (Jayne et al., 2000). In the MS-mode the mass range 10-300 amu was scanned over the entire particle population, while in the PToF mode, the size-dependent velocity distribution of the particles after expansion into the vacuum was determined by detecting a few specific masses. Using the MS-mode, the composition of the non-refractory fraction of the particles was measured and a few selected mass peaks that represent the material studied were selected (PSL - 28, 44, 64, 91 and 104, organics - 28, 38, 41, 44 and 64, and for ammonium salts - 15, 16, 17, 18, 28, 48 and 64). Then, the quadrupole mass spectrometer (QMS) was tuned to these mass peaks and the time of flight between a chopper and MS-detector was measured. Since we have calibrated the AMS PToF using PSL (see below) with a $m / z$ of 104 and measured our samples using $\mathrm{m} / \mathrm{z}$ of 44 for organic and 64 for sulfates a shift in the ions traveling time inside the quadruple mass spectrum can occur. This systematic shift can reach up to $40 \mu \mathrm{s}$ (104-44 transition and $20 \mu \mathrm{s}$ for 104-64 transition) resulting with a systematic error of underestimation between $<5 \%$ and $<4 \%$ for 100 to $200 \mathrm{~nm} \mathrm{~d}_{v a}$ of organics, respectively. For sulfate, the systematic error would be $<3 \%$ at $100 \mathrm{~nm}$ and $<2 \%$ at $200 \mathrm{~nm} \mathrm{~d}_{v a}$. The results present below were not corrected for this shift and we consider this error as a systematic possible error which does not effect the high precision of our experimental error.

The conversion of PToF to aerodynamic diameter employs an empirical calibration curve (Jayne et al., 2000; Jimenez et al., 2003). Calibrated polystyrene latex spheres of 102, 152 and $199 \mathrm{~nm}$ were used for generating a calibration curve every day and in addition validation tests were performed using the same PSLs between sample runs. The calibration curves were verified using ammonium sulfate (AS), ammonium bisulfate (ABS) and glucose particles which have known bulk densities. For each sample at least three different sizes were measured (mobility diameters 88,98 and $128 \mathrm{~nm}$, respectively), in addition each size was measured for three cycles integrating for 5 to $15 \mathrm{~min}$ (depending on the signal intensity). Table 1 summarizes the measured effective densities and the reciprocal of Jayne factor, S, for $60-230 \mathrm{~nm}$ (mobility diameter) AS, ABS and glucose particles. The derived effective densities agree well with literature values hence confirming the calibration procedure with very high certainty of $\pm 2 \%$.

3.2 Verification with ammonium sulfate and effects of aerosol generation

Using transmission electron microscopy (TEM) (Dick et al., 1998; Li et al., 2003; Perry et al., 1978), multi-angle light scattering (Dick et al., 1998; Perry et al., 1978) and by measuring particle beam divergence (Huffman et al., 2005) it was shown that by spraying and drying AS solutions, mildly aspherical particles with some significant variability form. Huffman et al. (2005) noticed that the lift shape factor of such AS particles increases with particle size ranging from 110 to $320 \mathrm{~nm}$. The decrease in $\rho_{\text {eff }}$ (caused by an increase 


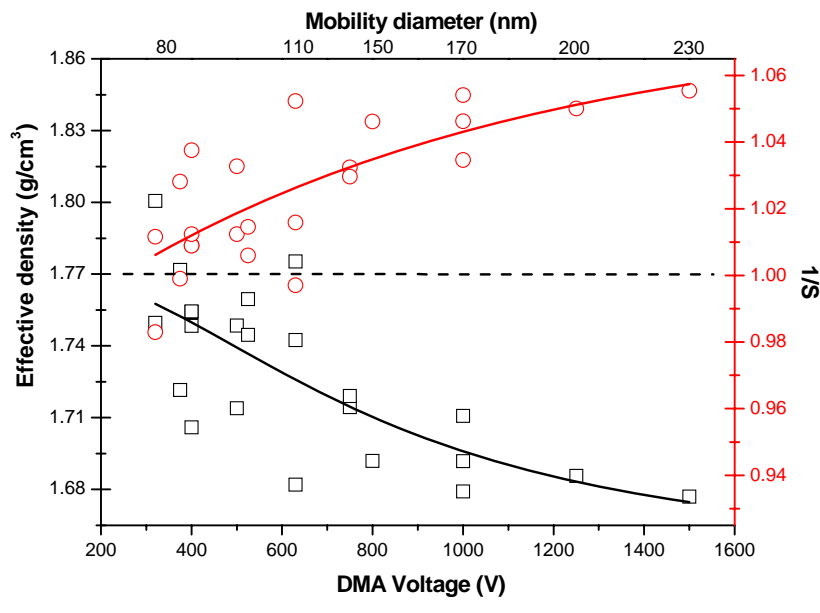

Fig. 2. The effect of particles shape on the AMS PToF values can be seen by the above figure emphasizing the relation between AS particles effective density (left axis, black squares) and the reciprocal of Jayne shape factor (right axis, red circles), as a function of particle mobility diameter (tested for particles ranging from 80 $230 \mathrm{~nm}$ ). The small values of the reciprocal Jayne shape factor and the effective density above the bulk density $\left(1.77 \mathrm{~g} / \mathrm{cm}^{3}\right)$ are a result of the statistic error $( \pm 2 \%)$ which can deviate between values of 1.73 to 1.81 for spherical particles and can even be broaden for non spherical particles. The lines are to guide the eye only.

of $\chi$ ) with increasing particle size have recently been demonstrated also by Zelenyuk et al. (2006) for AS particles with $160-500 \mathrm{~nm}$ mobility diameter. Figure 2 presents both the changes in the effective density of AS particles ranging from 80 to $230 \mathrm{~nm}$ (mobility diameter) and their coupled 1/S values. In the size range $80 \mathrm{~nm}$ to $120 \mathrm{~nm}$, our measured effective density scatter $\pm 2 \%$ around the literature value and for sizes $>160 \mathrm{~nm}$, our results show excellent agreement with Zelenyuk et al. (2005).

In previous experiments (Dinar et al., 2006a, b) we recognized the importance of conditioning the AS, SRFA and HULIS aerosol prior to drying (Sect. 3.3). In the present study it was found that conditioning had the same effect on AS, HULIS and SRFA particles, but a different effect on ABS particles. In the PToF mode of the AMS, single and multiple charged particles of the same electromobility class are separated according to their different vacuum aerodynamic diameter. Unconditioned AS particles yield a complex, multi peak size spectrum, they exhibit wide peaks with shoulders and a shift to shorter flight times compared to conditioned AS particles (Fig. 3). This behavior was eliminated by conditioning, yielding narrower and more stable size distributions. This indicates changes in particle morphology as discussed also in Zelenyuk et al. (2005). For ABS, conditioning resulted in different relative intensities of the single and multiple charged particles (Fig. 4). This can be attributed to high hygroscopicity of ABS, which retained residual water even at low relative humilities $<3 \%$ (Tang and Munkel- witz, 1994). This is corroborated by the fact that densities obtained from particle measurements are slightly lower $\left(\rho=1.74 \mathrm{~g} / \mathrm{cm}^{3}\right)$ than for crystalline ABS $\left(\rho=1.79 \mathrm{~g} / \mathrm{cm}^{3}\right)$.

The agreement of our effective densities with literature values (Sect. 4.1) and the sensitivity to second order effects of the conditioning step (Sect. 4.2) give us confidence that we are able to determine the effective densities of HS and atmospheric HULIS sample to better than $2 \%$.

\subsection{The effective density of SRFA bulk and fractions}

In previous investigations we compared between molecular weight-fractionated SRFA samples and HULIS samples for their: 1) ability to act as CCN (Dinar et al., 2006b) and 2) subsaturation water uptake (Dinar et al., 2006a). In the present study we measured the particle effective density of particles of the same samples. It is inherently assumed here that the SRFA, PPHA and the atmospheric HULIS samples are spherical (i.e. the particle shape factor is assumed to be 1). This assumption relies on a study by Hoffer et al. (2006) who showed SEM image of spherical HULIS dry particles produced in a similar manner to this study (i.e. they were extracted from biomass burning aerosols and were nebulized).

Table 2 summarizes the calculated effective densities, average molecular weight and aromaticity for all SRFA samples. Since it is expected that FA are the products of fragmentation of large HS (HA) (Diallo, 2003, \#181) we have added for comparison in Table 2 the measured effective densities of three PPHA samples (bulk, F2 and F5).

Figure 5 presents the relationship between the measured SRFA fractions density values and the average molecular weight (A) and aromaticity (B). It can be seen that the effective density of the SRFA fractions increases with its average molecular weight (Fig. 5a) and with the extent of aromaticity of the fraction (Fig. 5b). Figure 6 shows the relation with the carbon to oxygen ratio $(\mathrm{C} / \mathrm{O}$, taken from the elemental analysis as given in Table 3) (A) and with acidity (B). Since intermolecular interactions are the basis for molecular arrangement and packing which determine functional properties of agglomerates of molecules and the morphology of solids, it is expected to find correlations between the particles' chemo-physical properties and its density. Overall there is a tendency of the effective density to increase with increasing oxygen content and the oxygen to carbon ratio (Fig. 6a) and to decrease with increasing acidity (Fig. 6b). These observations together with previous results (Dinar et al., 2006a, b) are consistent with an overall behavior where the higher molecular weight fractions are less hygroscopic, more aromatic and better packed.

The trends in the correlations between effective density and these physical and chemical parameters are consistent with having less $\mathrm{H}$-or more $\mathrm{O}$-atoms with increasing $\mathrm{MW}$. If we take acidity as a measure of the number of carboxylic groups, which can form $\mathrm{H}$-bonds of some strength, and thus of overall H-bond importance, the increase of the density 
Table 2. Summary of the measured effective densities for the HS. For SRFA both number averaged molecular weight $\left(\mathrm{M}_{N}\right)$ and aromaticity are estimated based on UV correlation see Dinar et al. (2006b). Average molecular weight and aromaticity of PPHA samples were not determined since the UV correlation used is based on studies with FA samples (Dinar et al., 2006b).

\begin{tabular}{lllll}
\hline Sample & $\mathrm{M}_{N}$ & Aromaticity (\%) & Effective density $\left(\mathrm{g} \mathrm{cm}^{-3}\right)$ & Literature value \\
\hline SRFA Bulk & 570 & 20 & $1.47 \pm 0.02$ & $\sim 1.5$ (IHSS) \\
SRFA F1 & 450 & 12 & $1.39 \pm 0.02$ & \\
SRFA F2 & 520 & 16 & $1.42 \pm 0.01$ & \\
SRFA F3 & 620 & 23 & $1.49 \pm 0.02$ & \\
SRFA F4 & 720 & 30 & $1.52 \pm 0.01$ & Estimated to be 1.66 (Benedetti et \\
SRFA F5 & 740 & 32 & $1.51 \pm 0.01$ & al., 1996) \\
PPHA Bulk & & & $1.52 \pm 0.02$ & \\
& & & $1.56 \pm 0.01$ & \\
PPHA F2 & & & $1.58 \pm 0.03$ & \\
PPHA F5 & & & \\
\hline
\end{tabular}

Table 3. The organic components elemental analysis of the SRFA samples (Dinar et al., 2006b).

\begin{tabular}{llllllll}
\hline Sample & $\begin{array}{l}\mathrm{N} \\
\%\end{array}$ & $\mathrm{C}$ & $\mathrm{H}$ & $\mathrm{S}$ & $\mathrm{O}$ & $\mathrm{C} / \mathrm{O}$ & $\mathrm{H} / \mathrm{C}$ \\
& $\%$ & $\%$ & $\%$ & $\%$ & Mole ratio & Mole ratio \\
\hline F1 & $0.54 \pm 0.01$ & $54.78 \pm 0.03$ & $5.24 \pm 0.05$ & $\mathrm{n} / \mathrm{a}$ & 39.44 & 1.85 & 1.15 \\
$\mathrm{~F} 2$ & $0.63 \pm 0.003$ & $50.86 \pm 0.11$ & $4.71 \pm 0.06$ & $0.44 \pm 0.17$ & 43.37 & 1.56 & 1.11 \\
$\mathrm{~F} 3$ & $0.67 \pm 0.006$ & $50.63 \pm 0.35$ & $4.33 \pm 0.11$ & $0.31 \pm 0.11$ & 44.07 & 1.53 & 1.03 \\
$\mathrm{~F} 4$ & $0.77 \pm 0.05$ & $52.17 \pm 0.71$ & $4.56 \pm 0.19$ & $0.31 \pm 0.18$ & 42.20 & 1.64 & 1.05 \\
F5 & $0.73 \pm 0.01$ & $49.71 \pm 0.34$ & $4.01 \pm 0.13$ & $0.40 \pm 0.24$ & 45.16 & 1.47 & 0.97 \\
Bulk & $0.68 \pm 0.02$ & $53.36 \pm 1.03$ & $4.88 \pm 0.05$ & $0.26 \pm 0.12$ & 40.82 & 1.75 & 1.10 \\
\hline
\end{tabular}

with decreasing acidity suggests that H-bonds are either not the major intermolecular interaction which affects the particles' compaction trend or the H-bonds lead to looser structures owed to directional requirements of $\mathrm{H}$-bonding. The second strongest intermolecular interactions may be attributed to the presences of aromatic moieties which are known to be weaker and less defined. These interactions have multiple points of intermolecular contact with variable geometries and may contain a vast range of different functional groups (Hunter et al., 2001). Moreover, these interactions play a crucial part in biomolecules and pure organics selfassembly (Azriel and Gazit, 2001; Hunter et al., 2001; Whitten et al., 1998). Harmata and Barnes (1993) who also studied the packing and density of a complex organic substance concluded that the high densities observed indicate the efficiency of the packing, which are dominated by edge-to-face stacking of aromatic moieties. While this is not a proof, it illustrates that aromatic moieties can dominate stacking (and thus density) for a large complex molecule. The question remains, if such an effect - obviously less pronounced in the mixture of HULIS molecules - can explain the observation.

\subsection{The effective density of HULIS}

In addition to the SRFA samples, Fig. 5 also presents the relationship observed between the effective densities and the average molecular weight and the aromaticity of the three HULIS samples (see Table 4). This comparison supports our earlier conclusions (Dinar et al., 2006a, b) that SRFA and HULIS probably represent two different and distinct chemical populations. This distinction between SRFA and atmospheric HULIS is further demonstrated in Fig. 7 which shows the relation between the $\mathrm{CCN}$ dry diameter of activation at super-saturation $0.2,0.52$ and $1.03 \%$ to effective density for both SRFA and the HULIS samples extracted from ambient particles (Dinar et al., 2006b). Both samples show relationship between average molecular weight and aromaticity (Fig. 5). However, while SRFA effective densities increase with the average molecular weight and aromatic percent, the HULIS samples have an opposite tendency showing a reduction in effective density with increasing average molecular weight and aromatic percentage. Unfortunately, due to the small amount of these samples we were not able to conduct elemental analysis.

However, we postulate that as the samples age (mostly by oxidation) in the atmosphere, there is a reduction in the 


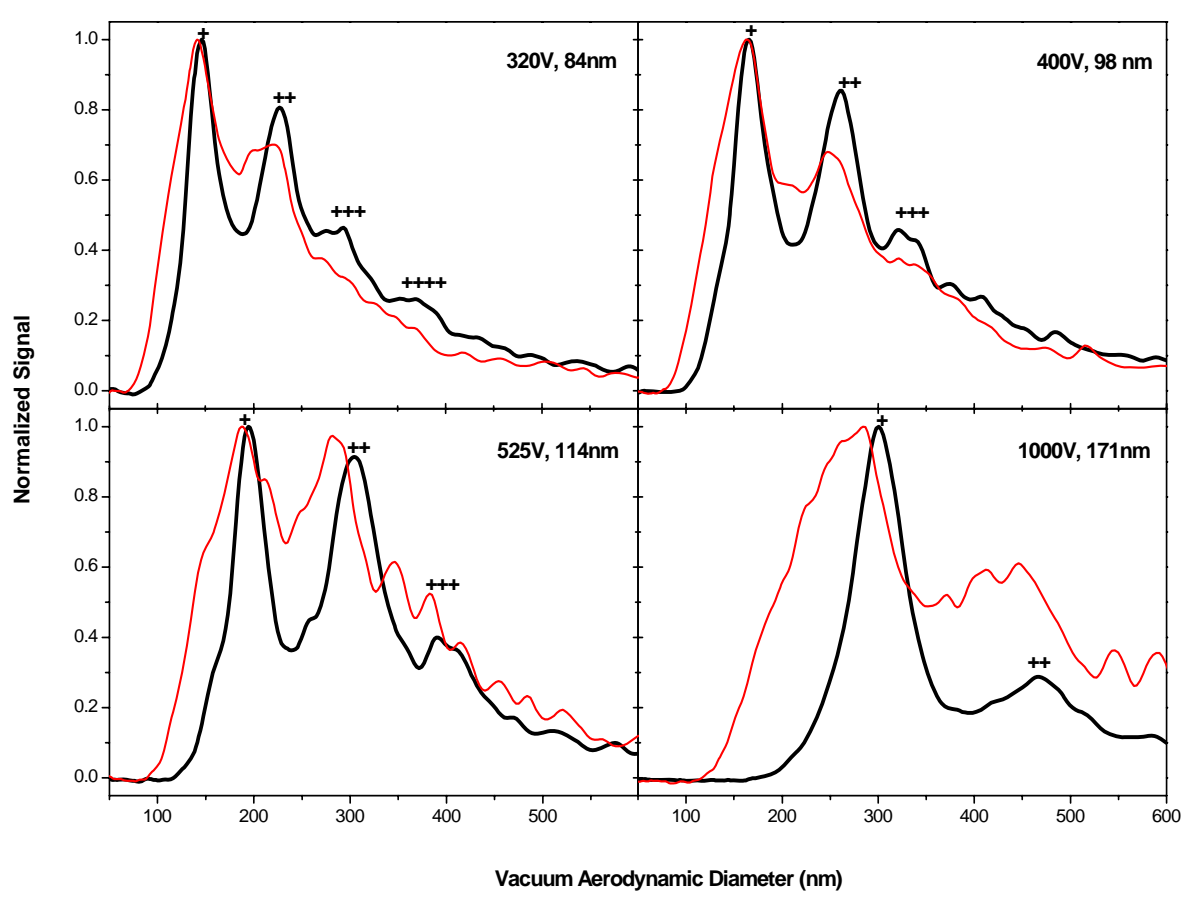

Fig. 3. The effect of conditioning on the vacuum aerodynamic diameter spectrum of different size selected (84-171 nm) AS particles. The black line represents the vacuum aerodynamic diameter of size selected AS particles following conditioning. The red line shows the spectrum without conditioning. Multiply charged particles are indicated.

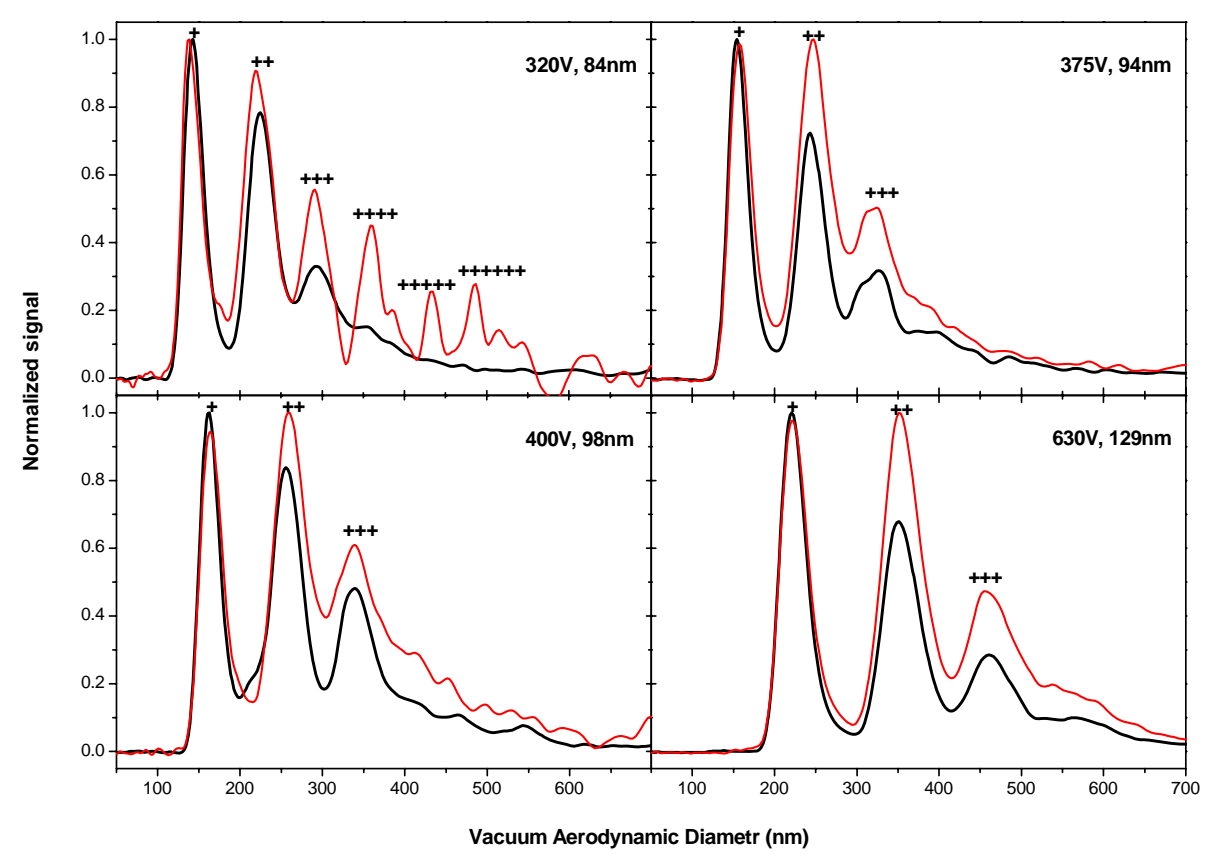

Fig. 4. The effect of conditioning after atomizing on the vacuum aerodynamic diameter spectrum of different size selected (84-129 nm) ABS particles. The black full line presents the vacuum aerodynamic diameter of size selected ABS particles which have undergone conditioning fallowed atomizing. For each size selected figure the red dashed line shows the spectrum without conditioning. Multiply charged particles are indicated. 
Table 4. Summary of the measured densities for FA-HULIS samples. Both number averaged molecular weight and aromaticity are estimated based on UV correlation as the SRFA samples (Dinar et al., 2006b).

\begin{tabular}{lllll}
\hline HULIS samples & $\mathrm{M}_{N}$ & Effective density $\left(\mathrm{g} \mathrm{cm}^{-3}\right)$ & Aromaticity $(\%)$ & Literature value (Hoffer et al., 2006) \\
\hline LBO-Night & 610 & $1.50 \pm 0.01$ & 20 & $1.50 \pm 0.02$ \\
LBO-Day & 410 & $1.72 \pm 0.03$ & 10 & $1.57 \pm 0.03$ \\
3WSFA & 500 & $1.57 \pm 0.03$ & 16 & \\
\hline
\end{tabular}
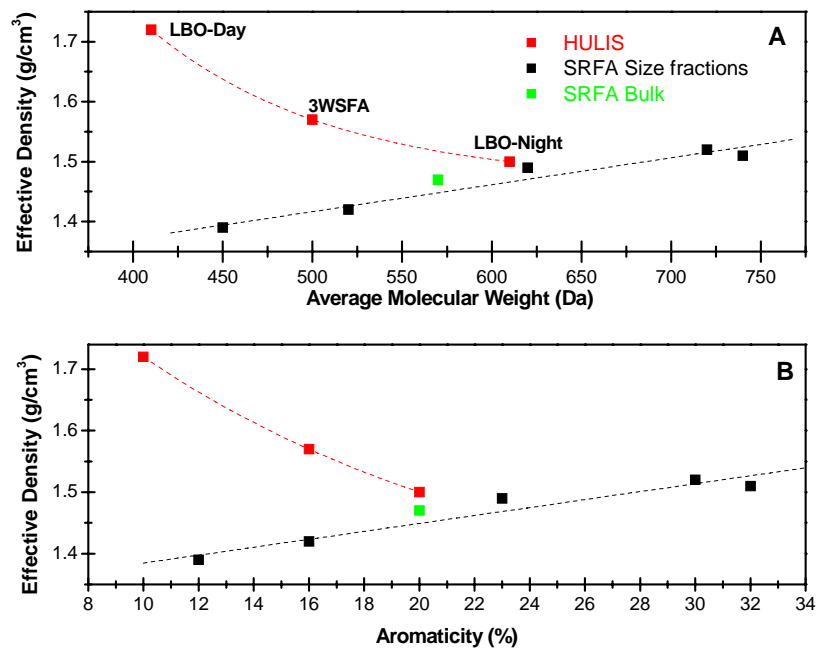

Fig. 5. Relationship between measured density values of SRFA

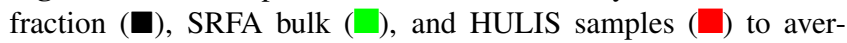
age molecular weight (A) and aromaticity (B). The lines are freely drawn to guide the eye.
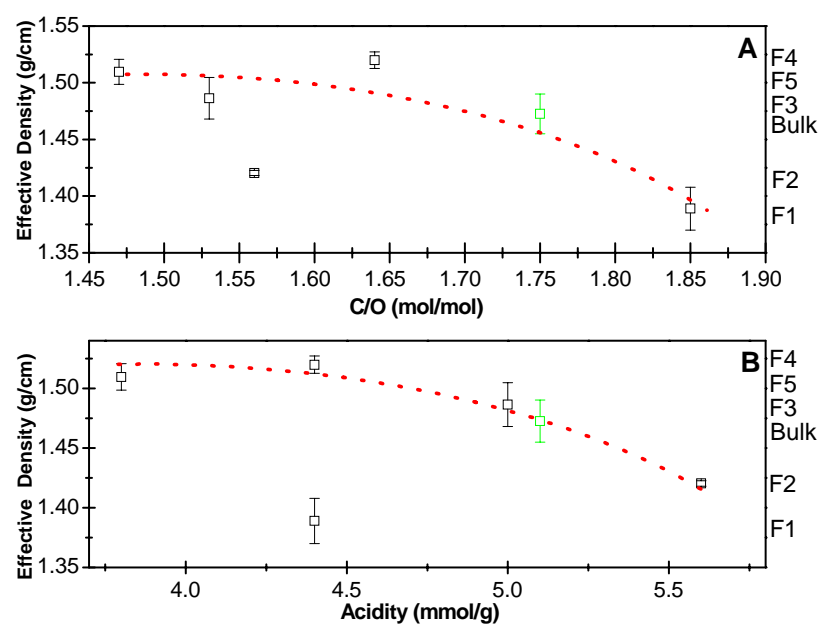

Fig. 6. The relationship between the measured effective density of SRFA samples to their C/O ratio (A) and their number of acidic groups $(\mathbf{B})$. The lines are freely drawn to guide the eye.

aromaticity and increase in the oxygen content. As a re-

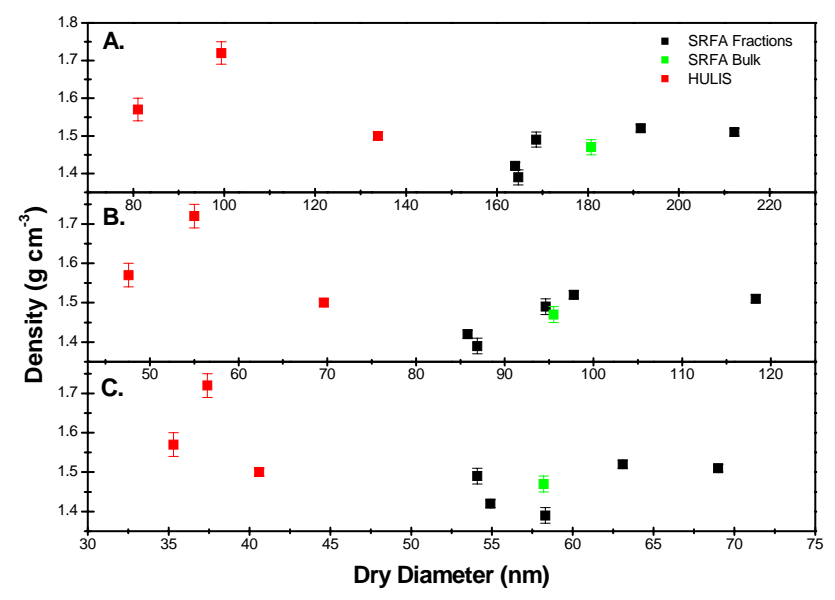

Fig. 7. The relationship between the measured effective densities

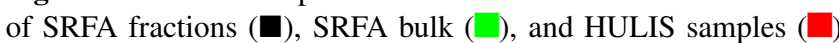
to average $\mathrm{CCN}$ dry diameter of activation at supersaturation $0.2 \%$ (a), $0.52 \%$ (b), and $1.03 \%$ (c). (note the different X-scale).

sult, the role of aromaticity decreases and the change in the oxidation state increases the hygroscopicity and the density. A similar trend in increasing effective density with photochemical aging may partly explain the observation of Pitz et al. (2003) who also observed an increase in particles' effective density from morning to the afternoon, due to change in chemistry and shape.

Only a few studies focused so far on determination of the density of ambient aerosol particles and its change due to aging in the atmosphere. All of them, though, estimated and measured the density of aerosol particles without detailed analysis of the chemical composition of these aerosols (McMurry et al., 2002; Pitz et al., 2003). Some of the studies focused on soot which has a low effective density, due to it's "fluffy" structure (McMurry et al., 2002; Slowik, 2004). As far as we know our results about the density of HULIS from biomass burning and pollution aerosols can be compared only to a recent study by Hoffer et al. (2006) who measured the density properties of HULIS extracts from day time and nighttime biomass burning smoke particles from Brazil. Hoffer et al. (2006) found that HULIS extracted from the nighttime smoke particles have a lower density then the daytime HULIS extracts, $1.50 \pm 0.02$ and 
$1.57 \pm 0.03$, respectively (Hoffer et al., 2006). The density of HULIS extracted from the pollution particles in this study $\left(1.57 \pm 0.03 \mathrm{~g} \mathrm{~cm}^{-3}\right)$ is close to the mean apparent particle density measured for urban aerosols in Germany by Pitz et al. $\left(1.6 \pm 0.5 \mathrm{~g} \mathrm{~cm}^{-3}\right)$ (Pitz et al., 2003).

Interestingly, comparison between the fresh wood burning HULIS extracts (LBO-Night) with the nighttime sample studied by Hoffer et al. (2006) indicate that both night samples have similar density, $1.50 \pm 0.02 \mathrm{~g} \mathrm{~cm}^{-3}$. These values are close to the density of cellulose $\left(1.5 \mathrm{~g} \mathrm{~cm}^{-3}\right)$ and its derivatives, starch $\left(1.53 \mathrm{~g} \mathrm{~cm}^{-3}, \mathrm{CRC}\right.$ handbook), sugar $\left(1.59 \mathrm{~g} \mathrm{~cm}^{-3}\right.$, CRC handbook) levoglucosan $\left(1.6 \mathrm{~g} \mathrm{~cm}^{-3}\right.$, ALDRICH) and other carbohydrates such as glucose (which was measured by us to be $1.53 \pm 0.02 \mathrm{~g} \mathrm{~cm}^{-3}$ ), possibly implying the presences of carbohydrates-like components in the LBO-Night HULIS extract. The HULIS extracted from the daytime smoke samples have a higher effective density of $1.57 \pm 0.03 \mathrm{~g} \mathrm{~cm}^{-3}$. The LBO-day sample in this study had a higher effective density, $1.72 \pm 0.03 \mathrm{~g} \mathrm{~cm}^{-3}$. The difference may be attributed to mixing between fresh and photochemically aged smoke in Brazil, while our collected particles during day time did not contain fresh smoke particles. As far as we know direct measurements of the density of daily average air pollution HULIS have not been conducted.

Acknowledgements. This work was supported by a grant from the Israel Academy of Sciences (grant \#162/05) and the Minerva Foundation. E. Dinar acknowledges a grant from the ESF-program INTROP.

Edited by: R. Volkamer

\section{References}

Abdul-Razzak, H. and Ghan, S. J.: Parameterization of the influence of organic surfactants on aerosol activation, J. Geophys. Res., 109, D03205, doi:03210.01029/02003JD004043, 2004.

Azriel, R. and Gazit, E.: Analysis of the structural and functional elements of the minimal active fragment of islet amyloid polypeptide (iapp) - an experimental support for the key role of the phenylalanine residue in amyloid formation, J. Biol. Chem., 276, 34 156-34 161, 2001.

Badger, C. L., George, I., Griffiths, P. T., Braban, C. F., Cox, R. A., and Abbatt, J. P. D.: Phase transitions and hygroscopic growth of aerosol particles containing humic acid and mixtures of humic acid and ammonium sulphate, Atmos. Chem. Phys., 6, 755-768, 2006, http://www.atmos-chem-phys.net/6/755/2006/.

Benedetti, M. F., vanRiemsdik, W. H., and Koopal, L. K.: Humic substances considered as a heterogeneous donnan gel phase, Environ. Sci. Technol., 30, 1805-1813, 1996.

Brooks, S. D., DeMott, P. J., and Kreidenweis, S. M.: Water uptake by particles containing humic materials and mixtures of humic materials with ammonium sulfate, Atmos. Environ., 38, 18591868, 2004.

Chan, M. N. and Chan, C. K.: Hygroscopic properties of two model humic-like substances and their mixtures with inorganics of atmospheric importance, Environ. Sci. Tech., 37, 5109-5115, 2003.

Cheng, M. T. and Tsai, Y. I.: Characterization of visibility and atmospheric aerosols in urban, suburban, and remote areas, Sci. Total Environ., 263, 101-114, 2000.

DeCarlo, P. F., Slowik, J. G., Worsnop, D. R., Davidovits, P., and Jimenez, J. L.: Particle morphology and density characterization by combined mobility and aerodynamic diameter measurements. Part 1: Theory, Aerosol. Sci. Technol., 38, 1185-1205, 2004.

Decesari, S., Facchini, M. C., Matta, E., Lettini, F., Mircea, M., Fuzzi, S., Tagliavini, E., and Putaud, J. P.: Chemical features and seasonal variation of fine aerosol water-soluble organic compounds in the po valley, italy, Atmos. Environ., 35, 3691-3699, 2001.

Diallo, M. S., Simpson, A., Gassman, P., Faulon, J. L., Johnson, J. H., Goddard, W. A., and Hatcher, P. G.: 3-d structural modeling of humic acids through experimental characterization, computer assisted structure elucidation and atomistic simulations. 1. Chelsea soil humic acid, Environ. Sci. Technol., 37, 1783-1793, 2003.

Dick, W. D., Ziemann, P. J., Huang, P. F., and McMurry, P. H.: Optical shape fraction measurements of submicrometre laboratory and atmospheric aerosols, Measure, Sci. Technol., 9, 183-196, 1998.

Dinar, E., Taraniuk, I., Graber, E. R., Anttila, T., Mentel, T. F., and Rudich, Y.: Hygroscopic growth of model and atmospheric hulis, J. Geophys. Res. J. Geophys. Res.-Atmos., in press, 2006a.

Dinar, E., Taraniuk, I., Graber, E. R., Katsman, S., Moise, T., Anttila, T., Mentel, T. F., and Rudich, Y.: Cloud condensation nuclei properties of model and atmospheric hulis, Atmos. Chem. Phys., 6, 2465-2481, 2006b.

Dusek, U., Frank, G. P., Hildebrandt, L., Curtius, J., Schneider, J., Walter, S., Chand, D., Drewnick, F., Hings, S., Jung, D., Borrmann, S., and Andreae, M. O.: Size matters more than chemistry for cloud-nucleating ability of aerosol particles, Science, 312, 1375-1378, 2006.

Facchini, M. C., Fuzzi, S., Zappoli, S., Andracchio, A., Gelencser, A., Kiss, G., Krivacsy, Z., Meszaros, E., Hansson, H. C., Alsberg, T., and Zebuhr, Y.: Partitioning of the organic aerosol component between fog droplets and interstitial air, J. Geophys. Res., 104, 26821-26 832, 1999.

Fuzzi, S., Decesari, S., Facchini, M. C., Matta, E., Mircea, M., and Tagliavini, E.: A simplified model of the water soluble organic component of atmospheric aerosols, Geophys. Res. Lett., 28, 4079-4082, 2001.

Gelencser, A., Meszaros, T., Blazso, M., Kiss, G., Krivacsy, Z., Molnar, A., and Meszaros, E.: Structural characterisation of organic matter in fine tropospheric aerosol by pyrolysis-gas chromatography-mass spectrometry, J. Atmos. Chem., 37, 173$183,2000$.

Graber, E. R. and Rudich, Y.: Atmospheric hulis: How humic-like are they? A comprehensive and critical review, Atmos. Chem. Phys., 6, 729-753, 2006,

http://www.atmos-chem-phys.net/6/729/2006/.

Gysel, M., Weingartner, E., Nyeki, S., Paulsen, D., Baltensperger, U., Galambos, I., and Kiss, G.: Hygroscopic properties of water-soluble matter and humic-like organics in atmospheric fine aerosol, Atmos. Chem. Phys., 4, 35-50, 2004, http://www.atmos-chem-phys.net/4/35/2004/. 
Haiber, S., Herzog, H., Burba, P., Gosciniak, B., and Lambert, J.: Two-dimensional $\mathrm{nmr}$ studies of size fractionated suwannee river fulvic and humic acid reference, Environ. Sci. Technol., 35, 4289-4294, 2001.

Hanel, G. and Thudium, J.: Mean bulk densities of samples of dry atmospheric aerosol-particles - summary of measured data, Pure Appl. Geophys., 115, 799-803, 1977.

Hansen, J., Sato, M., Ruedy, R., Nazarenko, L., Lacis, A., Schmidt, G. A., Russell, G., Aleinov, I., Bauer, M., Bauer, S., Bell, N., Cairns, B., Canuto, V., Chandler, M., Cheng, Y., Del Genio, A., Faluvegi, G., Fleming, E., Friend, A., Hall, T., Jackman, C., Kelley, M., Kiang, N., Koch, D., Lean, J., Lerner, J., Lo, K., Menon, S., Miller, R., Minnis, P., Novakov, T., Oinas, V., Perlwitz, J., Perlwitz, J., Rind, D., Romanou, A., Shindell, D., Stone, P., Sun, S., Tausnev, N., Thresher, D., Wielicki, B., Wong, T., Yao, M., and Zhang, S.: Efficacy of climate forcings, J. Geophys. Res., 110, D18104, doi:18110.11029/12005JD005776, 2005.

Harmata, M. and Barnes, C. L.: 5-alpha,8-beta,14-alpha,17alpha-5,6,8,9,14,15,17,18-octahydro-5,17/8,14 -diepoxydibenzo[e,e']benzo[1,2-a-4,5-a']dicyclooctene, Acta Crystallographica Section C-Crystal Structure Communications, 49, 115-116, 1993.

Hasan, H. and Dzubay, T. G.: Apportioning light extinction coefficients to chemical-species in atmospheric aerosol, Atmos. Environ., 17, 1573-1581, 1983.

Hoffer, A., Gelencs'er, A., Guyon, P., Kiss, G., Schmid, O., Frank, G., Artaxo, P., and Andreae, M. O.: Optical properties of humic-like substances (hulis) in biomass-burning aerosols, Atmos. Chem. Phys., 6, 3563-3570, 2006,

http://www.atmos-chem-phys.net/6/3563/2006/.

Hoffer, A., Kiss, G., Blazso, M., and Gelencser, A.: Chemical characterization of humic-like substances (hulis) formed from a lignin-type precursor in model cloud water, Geophys. Res. Lett., 31, L06115, doi:06110.01029/02003GL018962, 2004.

Huang, Y. C. T., Ghio, A. J., Stonehuerner, J., McGee, J., Carter, J. D., Grambow, S. C., and Devlin, R. B.: The role of soluble components in ambient fine particles-induced changes in human lungs and blood, Inhal Tox., 15, 327-342, 2003.

Huffman, J. A., Jayne, J. T., Drewnick, F., Aiken, A. C., Onasch, T., Worsnop, D. R., and Jimenez, J. L.: Design, modeling, optimization, and experimental tests of a particle beam width probe for the aerodyne aerosol mass spectrometer, Aerosol Sci. Technol., 39, 1143-1163, 2005.

Hunter, C. A., Lawson, K. R., Perkins, J., and Urch, C. J.: Aromatic interactions, J. Chem. Perkin. Soc., 651-669, 2001.

Jacobson, M. C., Hansson, H. C., Noone, K. J., and Charlson, R. J.: Organic atmospheric aerosols: Review and state of the science, Rev. Geophys., 38, 267-294, 2000.

Jayne, J. T., Leard, D. C., Zhang, X. F., Davidovits, P., Smith, K. A., Kolb, C. E., and Worsnop, D. R.: Development of an aerosol mass spectrometer for size and composition analysis of submicron particles, Aerosol Sci. Technol., 33, 49-70, 2000.

Jimenez, J. L., Jayne, J. T., Shi, Q., Kolb, C. E., Worsnop, D. R., Yourshaw, I., Seinfeld, J. H., Flagan, R. C., Zhang, X. F., Smith, K. A., Morris, J. W., and Davidovits, P.: Ambient aerosol sampling using the aerodyne aerosol mass spectrometer, J. Geophys. Res., 108, 8425, doi:8410.1029/2001JD001213, 2003.

Jones, M. N., Birkett, J. W., Wilkinson, A. E., Hesketh, N., Livens, F. R., Bryan, N. D., Lead, J. R., Hamiltontaylor, J., and Tipping,
E.: Experimental-determination of partial specific volumes of humic substances in aqueous-solutions, Analytica Chimica Acta, 314, 149-159, 1995.

Kanakidou, M., Seinfeld, J. H., Pandis, S. N., Barnes, I., Dentener, F. J., Facchini, M. C., Van Dingenen, R., Ervens, B., Nenes, A., Nielsen, C. J., Swietlicki, E., Putaud, J. P., Balkanski, Y., Fuzzi, S., Horth, J., Moortgat, G. K., Winterhalter, R., Myhre, C. E. L., Tsigaridis, K., Vignati, E., Stephanou, E. G., and Wilson, J.: Organic aerosol and global climate modelling: A review, Atmos. Chem. Phys., 5, 1053-1123, 2005,

http://www.atmos-chem-phys.net/5/1053/2005/.

Kappos, A. D., Bruckmann, P., Eikmann, T., Englert, N., Heinrich, U., Hoppe, P., Koch, E., Krause, G. H. M., Kreyling, W. G., Rauchfuss, K., Rombout, P., Schulz-Klemp, V., Thiel, W. R., and Wichmann, H. E.: Health effects of particles in ambient air, Int. J. Hyg. Environ. Health, 207, 399-407, 2004.

Katrib, Y., Martin, S. T., Rudich, Y., Davidovits, P., Jayne, J. T., and Worsnop, D. R.: Density changes of aerosol particles as a result of chemical reaction, Atmos. Chem. Phys., 5, 275-291, 2005, http://www.atmos-chem-phys.net/5/275/2005/.

Kaufman, Y. J., Koren, I., Remer, L. A., Rosenfeld, D., and Rudich, Y.: The effect of smoke, dust, and pollution aerosol on shallow cloud development over the atlantic ocean, Proc. Natl. Acad. Sci. USA, 102, 11 207-11 212, 2005.

Kaufman, Y. J., Tanré, D., and Boucher, O.: A satellite view of aerosols in the climate system, Nature, 419, 215-223, 2002.

Kiss, G., Tombacz, E., and Hansson, H. C.: Surface tension effects of humic-like substances in the aqueous extract of tropospheric fine aerosol, J. Atmos. Chem., 50, 279-294, 2005.

Kiss, G., Varga, B., Galambos, I., and Ganszky, I.: Characterization of water-soluble organic matter isolated from atmospheric fine aerosol, J. Geophys. Res., 107, 8339 , doi:8310.1029/2001JD000603, 2002.

Koren, I., Kaufman, Y. J., Rosenfeld, D., Remer, L. A., and Rudich, Y.: Aerosol invigoration and restructuring of atlantic convective clouds, Geophys. Res. Lett., 32, L14828, doi:14810.11029/12005GL023187, 2005.

Krivacsy, Z., Gelencser, A., Kiss, G., Meszaros, E., Molnar, A., Hoffer, A., Meszaros, T., Sarvari, Z., Temesi, D., Varga, B., Baltensperger, U., Nyeki, S., and Weingartner, E.: Study on the chemical character of water soluble organic compounds in fine atmospheric aerosol at the jungfraujoch, J. Atmos. Chem., 39, 235-259, 2001.

Li, J., Posfai, M., Hobbs, P. V., and Buseck, P. R.: Individual aerosol particles from biomass burning in southern africa: 2, compositions and aging of inorganic particles, J. Geophys. Res., 108, 8484, doi:8410.1029/2002JD002310, 2003.

Lohmann, U., Koren, I., and Kaufman, Y. J.: Disentangling the role of microphysical and dynamical effects in determining cloud properties over the atlantic, Geophys. Res. Lett., 33, L09802, doi:09810.01029/02005GL024625, 2006.

Malm, W. C., Day, D. E., Kreidenweis, S. M., Collett, J. L., and Lee, T.: Humidity-dependent optical properties of fine particles during the big bend regional aerosol and visibility observational study, J. Geophys. Res., 108, 4279, doi:4210.1029/2002JD002998, 2003.

Mayol-Bracero, O. L., Guyon, P., Graham, B., Roberts, G., Andreae, M. O., Decesari, S., Facchini, M. C., Fuzzi, S., and Artaxo, P.: Water-soluble organic compounds in biomass burning 
aerosols over amazonia - 2. Apportionment of the chemical composition and importance of the polyacidic fraction, J. Geophys. Res., 107, 8091, doi:8010.1029/2001JD000522, 2002.

McDonnell, W. F., Nishino-Ishikawa, N., Petersen, F. F., Chen, L. H., and Abbey, D. E.: Relationships of mortality with the fine and coarse fractions of long-term ambient pm10 concentrations in nonsmokers, J. Ecpos. Environ. Epi., 10, 427-436, 2000.

McMurry, P. H., Wang, X., Park, K., and Ehara, K.: The relationship between mass and mobility for atmospheric particles: A new technique for measuring particle density, Aerosol Sci. Technol., 36, 227-238, 2002.

Mircea, M., Facchini, M. C., Decesari, S., Fuzzi, S., and Charlson, R. J.: The influence of the organic aerosol component on ccn supersaturation spectra for different aerosol types, Tellus Ser. BChem. Phys. Meteorol., 54, 74-81, 2002.

Murphy, D. M., Cziczo, D. J., Hudson, P. K., Schein, M. E., and Thomson, D. S.: Particle density inferred from simultaneous optical and aerodynamic diameters sorted by composition, J. Aerosol Sci., 35, 135-139, 2004.

Nenes, A., Charlson, R. J., Facchini, M. C., Kulmala, M., Laaksonen, A., and Seinfeld, J. H.: Can chemical effects on cloud droplet number rival the first indirect effect?, Geophys. Res. Lett., 29, 1848, doi:1810.1029/2002GL015295, 2002.

Novakov, T. and Penner, J. E.: Large contribution of organic aerosols to cloud-condensation nuclei concentrations, Nature, 365, 823-826, 1993.

Park, K., Cao, F., Kittelson, D. B., and McMurry, P. H.: Relationship between particle mass and mobility for diesel exhaust particles, Environ. Sci. Technol., 37, 577-583, 2003.

Park, K., Kittelson, D. B., Zachariah, M. R., and McMurry, P. H.: Measurement of inherent material density of nanoparticle agglomerates, J. Nanoparticle Res., 6, 267-272, 2004.

Perry, R. J., Hunt, A. J., and Huffman, D. R.: Experimental determinations of mueller scattering matrices for nonspherical particles, Appl. Opt., 17, 2700-2710, 1978.

Pitz, M., Cyrys, J., Karg, E., Wiedensohler, A., Wichmann, H. E., and Heinrich, J.: Variability of apparent particle density of an urban aerosol, Environ. Sci. Technol., 37, 4336-4342, 2003.

Poschl, U.: Atmospheric aerosols: Composition, transformation, climate and health effects, Angew. Chem.-Int. Edit., 44, 75207540, 2005.

Ramanathan, V., Crutzen, P. J., Kiehl, J. T., and Rosenfeld, D.: Atmosphere, aerosols, climate, and the hydrological cycle, Science, 294, 2119-2124, 2001.

Reid, P. M., Wilkinson, A. E., Tipping, E., and Jones, M. N.: Determination of molecular-weights of humic substances by analytical (uv scanning) ultracentrifugation, Geochim. Cosmochim. Acta, 54, 131-138, 1990.

Rissman, T. A., Nenes, A., and Seinfeld, J. H.: Chemical amplification (or dampening) of the twomey effect: Conditions derived from droplet activation theory, J. Atmos. Sci., 61, 919-930, 2004.

Samburova, V., Zenobi, R., and Kalberer, M.: Characterization of high molecular weight compounds in urban atmospheric particles, Atmos. Chem. Phys., 5, 2163-2170, 2005, http://www.atmos-chem-phys.net/5/2163/2005/.
Saxena, P. and Hildemann, L. M.: Water-soluble organics in atmospheric particles: A critical review of the literature and application of thermodynamics to identify candidate compounds, J. Atmos. Chem., 24, 57-109, 1996.

Schkolnik, G. and Rudich, Y.: Detection and quantification of levoglucosan in atmospheric aerosols: A review, Anal. Bioanal. Chem., 385, 26-33, 2006.

Slowik, J. G., Stainken, K., Davidovits, P., Williams, L. R., Jayan, J. T., Kold, C. E., Worsnop, D. R., Rudich, Y., DeCarlo, P. F., and Jimenez, J. L.: Particle morphology and density characterization by combined mobility and aerodynamic diameter measurements. Part 2: Application to combustion-generated soot aerosols as a function of fuel equivalence ratio, Aerosol Sci. Technol., 38, 1206-1222, 2004.

Svenningsson, B., Rissler, J., Swietlicki, E., Mircea, M., Bilde, M., Facchini, M. C., Decesari, S., Fuzzi, S., Zhou, J., Mønster, J., and T., R.: Hygroscopic growth and critical supersaturations for mixed aerosol particles of inorganic and organic compounds of atmospheric relevance, Atmos. Chem. Phys., 6, 1937-1952, 2006, http://www.atmos-chem-phys.net/6/1937/2006/.

Swift, R. S.: Methods of soil analysis, part 3. Chemical methods, Organic matter characterization (chap 35), 1018-1020, 1996.

Tang, I. N. and Munkelwitz, H. R.: Water activities, densities, and refractive-indexes of aqueous sulfates and sodiumnitrate droplets of atmospheric importance, J. Geophys. Res., 99, 18 801-18 808, 1994.

Varga, B., Kiss, G., Ganszky, I., Gelencser, A., and Krivacsy, Z.: Isolation of water-soluble organic matter from atmospheric aerosol, Talanta, 55, 561-572, 2001.

Whitten, D. G., Chen, L. H., Geiger, H. C., Perlstein, J., and Song, X. D.: Self-assembly of aromatic-functionalized amphiphiles: The role and consequences of aromatic-aromatic noncovalent interactions in building supramolecular aggregates and novel assemblies, J. Phys. Chem. B, 102, 10 098-10 111, 1998.

Zappoli, S., Andracchio, A., Fuzzi, S., Facchini, M. C., Gelencser, A., Kiss, G., Krivacsy, Z., Molnar, A., Meszaros, E., Hansson, H. C., Rosman, K., and Zebuhr, Y.: Inorganic, organic and macromolecular components of fine aerosol in different areas of europe in relation to their water solubility, Atmos. Environ., 33, 27332743, 1999.

Zelenyuk, A., Cai, Y., Chieffo, L., and Imre, D.: High precision density measurements of single particles: The density of metastable phases, Aerosol Sci. Technol., 39, 972-986, 2005.

Zelenyuk, A., Cai, Y., and Imre, D.: From agglomerates of spheres to irregularly shaped particles: Determination of dynamic shape factors from measurements of mobility and vacuum aerodynamic diameters, Aerosol Sci. Technol., 40, 197-217, 2006.

Zelenyuk, A. and Imre, D.: Single particle laser ablation time-offlight mass spectrometer: An introduction to splat, Aerosol Sci. Technol., 39, 554-568, 2005. 